\title{
Gri Tahmin Modelleri ile Toplam Enerji Talep Tahmini: Türkiye Örneği
}

Forecasting Total Energy Demand with Grey Prediction Models: The Case of Turkey

\author{
Hüseyin Avni ES* \\ Karadeniz Teknik Üniversitesi, Mühendislik Fakültesi, Endüstri Mühendisliği Bölümü, 61080, Trabzon
}

• Geliş tarihi / Received: 18.01.2020 • Düzeltilerek geliş tarihi / Received in revised form: 07.06.2020 • Kabul tarihi / Accepted: 14.06 .2020

\section{$\ddot{O} z$}

Gelişen ve gelişmekte olan ülkelerin, sürdürülebilir enerji politikaları belirleyebilmesinde enerji talep tahminlerine ihtiyaç duyulmaktadır. Gri tahmin modelleri, önceden herhangi bir ön bilgiye ihtiyaç duymadan sınırlı veri ile başarılı tahminler gerçekleştirebilmektedir. Bu çalışmada, son dönemde önemli ekonomik ve sosyal gelişme gösteren Türkiye'nin toplam enerji talebi için Gri tahmin modelleri dikkate alınmıştır. Gri tahmin; zaman serisi ve sebep-sonuç ilişkisine dayalı çeşitli tahmin modellerini içermektedir. Çalışma kapsamında; zaman serisi modellerinden GM(1,1) ve Gri Verhulst ile sebep-sonuç ilişkisine dayalı $\mathrm{GM}(0, \mathrm{~N})$ ve $\mathrm{GM}(1, \mathrm{~N})$ modelleri olmak üzere dört farklı gri tahmin modeli ele alınmıştır. İki çeşit tahmin yapısının kullanılmasındaki amaç; son dönemdeki trendin zaman serisi ile yakalanması ve enerji talebindeki değişimin sebep-sonuç ilişkisiyle elde edilmesi sağlanarak güvenilir ve güçlü tahminlere ulaşmaktır. GM $(1,1)$ ve Gri Verhulst modelleri geçmiş toplam enerji tüketim verileri ile kurulmuştur. GM $(0, N)$ ve GM $(1, N)$ modellerinde ise; GSYH, nüfus, ithalat, ihracat ve bina yüzölçümü bağımsız değişkenleri kullanılarak GM $(0,6)$ ve GM $(1,6)$ modelleri oluşturulmuştur. Kurulan tüm modeller performans ölçütlerine göre kıyaslanmış, başarılı tahmin gerçekleştiren üstün modellerin GM $(1,1)$ ve GM $(1,6)$ olduğu belirlenmiştir. Sonuç olarak; GM $(1,1)$ ile zaman serisi ve GM $(1,6)$ ile yüksek ve düşük senaryo bazlı olmak üzere Türkiye toplam enerji talebi 2025 yılına kadar tahmin edilmiştir.

Anahtar kelimeler: Gri Tahmin Modelleri, Tahmin, Toplam Enerji Talebi, Türkiye

\begin{abstract}
Energy demand forecasts are needed for developing and emerging countries to be able to determine sustainable energy policies. Grey prediction models can make successful predictions with limited data without the need for any prior information. In this study, Grey prediction models are considered for the total energy demand of Turkey that shows significant economic and social development in recent years. Grey prediction includes forecasting models based on time series and cause-effect relationships. Four different grey prediction models including GM $(1,1)$ and Grey Verhulst from the time series models, and GM $(0, N)$ and $G M(1, N)$ based on the cause-effect relationships were discussed. The purpose of using two types of forecasting structures is to achieve reliable and strong forecasts by capturing the recent trend with the time series and obtaining the change in energy demand by cause-effect relationship. GM (1,1) and Grey Verhulst model has been established with past total energy consumption data. By using independent variables of GDP, population, import, export and building surface area for $G M(0, N)$ and $G M(1, N)$ models, GM $(0,6)$ and $G M(1,6)$ models were formed. All applied models have been compared according to performance criteria, GM $(1,1)$ and GM $(1,6)$ have been designated to be superior models that performed successful predictions. As a result; Turkey's total energy demand has been forecasted up to 2025 with GM $(1,1)$ based on time series and GM $(1,6)$ including high and low scenarios.
\end{abstract}

Keywords: Grey Prediction Models, Forecasting, Total Energy Demand, Turkey

*Hüseyin Avni ES; avnies@ktu.edu.tr; Tel: (0462) 37741 35; orcid.org/0000-0003-4987-0173 


\section{Giriş}

Enerji, ülkelerin sürdürülebilir gelişme ve kalkınma hedefleri için hayati öneme sahip stratejik bir bileşendir. Sanayileşme, nüfus artışı, refah seviyesinin yükselmesi gibi etkenler nedeniyle enerjiye olan talep dünya genelinde artış göstermektedir. 2000-2018 yılları arasında, dünyada toplam enerjiye olan talep \%48 oranında artarak 13865 milyon ton eşdeğer petrol (mtep) seviyesine ulaşmıştır (BP, 2019). Bununla birlikte bu dönem içerisindeki nüfus yaklaşık \%24 oranında artarak 7.6 milyar düzeyine yükselmiştir. Refah seviyesinin bir göstergesi olan GDP ise bu dönemde \%156 artarak 86 trilyon dolar seviyesine ulaşmıştır (Worldbank, 2020). Bu göstergelerdeki artış toplam enerji talebi etkilemekte ve bu artış eğiliminin gelecek dönemlerde de devam etmesi beklenmektedir. Dünyadaki eğilime benzer şekilde Türkiye de; altyapısını geliştirme, kalkınma hedeflerini gerçekleştirme, sosyal refahı artırma ve sanayi sektörünü uluslararası düzeyde rekabet edebilecek bir noktaya çıkarma çabas1 içerisindedir. $\mathrm{Bu}$ hedefler çerçevesinde; Türkiye'nin 2000 y1lında 170 milyar TL olan GSYH değeri, 2018 y1lında 3,7 trilyon TL seviyesine yükselmiştir. Ayrıca, 2018 yılında Türkiye nüfusu 2000 y1lına göre $\% 21$ artarak 82 milyon düzeyine ulaşmıştır. (TUIKK, 2020). Gelişen sanayi ve büyüyen nüfus ile birlikte Türkiye'de enerji talebi son dönemde önemli derecede artış göstermiştir. 2000-2018 yılları arasında, toplam enerjiye olan talep \% 110 artarak 154 mtep seviyesine ulaşmıştır. Toplam enerji tüketiminin \%31.6's1 petrol, \%26.5'i doğalgaz, $\% 27.6$ 's1 kömür, \%8.8'i hidroelektrik ve \%5.6's1 ise diğer yenilenebilir enerji kaynaklarından elde edilmiştir (BP, 2019). Özellikle petrol ve doğalgaz rezervleri bakımından kendi ihtiyacinı karş1layamayan bir ülke konumunda olan Türkiye için toplam enerji talebinin karşılanması, sanayileşmenin ve sürdürülebilir kalkınmanın gerçekleştirilebilmesindeki en önemli faktörlerdendir. Bu nedenle Türkiye toplam enerji talebinin doğru ve güvenilir tahminlerinin elde edilmesi, uzun dönemli ve kararlı enerji politikalarının belirlenmesi açısından oldukça önem arz etmektedir.

Enerji talebinin önemi nedeniyle literatürde birçok farklı tahmin tekniği ile çalışmalar gerçekleştirilmektedir. $\mathrm{Bu}$ yöntemlere örnek olarak; Box-Jenkins (Boran, 2014), regresyon modelleri (Bessec ve Fouquau, 2008), genetik algoritma (Lee ve Tong, 2011), parçacık sürü optimizasyonu (Ünler, 2008), yapay sinir ağları (Hamzacebi vd., 2019), destek vektör makineleri
(Li vd., 2018), bulanık mantık (Küçükali ve Barış, 2010), gri tahmin (Hamzaçebi ve Es, 2014) verilebilir. Literatürde yer alan derleme makalelerinden enerji talep tahmin modelleri ile ilgili olarak daha ayrıntılı bilgilere ulaşılabilir (Suganti ve Samuel, 2012; Salisu ve Ayinde, 2016). Son dönemlerde toplam enerji talebi ile ilgili olarak çeşitli çalışmalar literatürde yer almaktadır. Salcedo-Sanz ve arkadaşları, hesaplamalı zekâ algoritmaları kullanarak makroekonomik değişkenlerden bir yıllık enerji talep tahmin modeli geliştirmişlerdir (SalcedoSanz vd., 2015). Sánchez-Oro ve arkadaşları yaptıkları çalışmada İspanya'nın toplam enerji talebi için değişken komşu arama ve aşırı makine öğrenmesi algoritmasını birleştiren bir yaklaşım önermişlerdir (Sánchez-Oro vd., 2016). Wei ve Yanfeng çalışmalarında, dalgacık dönüşümüne dayalı gelişmiş bir Gri Markov zincir modeli kullanarak Çin'in enerji arzı ve talebi üzerine araştırma yapmışlardır (Wei ve Yanfeng, 2017). Wang ve arkadaşları çalışmalarında, Çin ve Hindistan'daki enerji talebini daha doğru tahmin etmek için gri teoriye dayalı tek doğrusal, hibritdoğrusal ve doğrusal olmayan tahmin teknikleri geliştirmişlerdir (Wang vd., 2018). Çeşitli tahmin teknikleriyle Türkiye'ye yönelik enerji talep tahmin çalışmaları da yapılagelmektedir. Aydın yaptığı çalışmada, ekonomik ve demografik faktörlere dayalı regresyon modelleri ile başarılı enerji tüketim modeli kurmuştur (Aydın, 2014). Es ve arkadaşları, YSA ile 1970-2010 yılları arasındaki sosyo-ekonomik gösterge verilerini kullanarak net enerji talebi projeksiyonunda bulunmuşlardır (Es vd., 2014). Bayramoğlu ve arkadaşları çalışmalarında birincil enerji talebi için Anfis modelini kurmuşlar ve 2030 y1lına kadar talep tahmininde bulunmuşlardır (Bayramoğlu vd., 2017). Bu iki çalışma Türkiye özelinde ayrıntılı literatür özetleri sunmaktadır (Es vd., 2014; Bayramoğlu vd., 2017). Gerçekleştirilen çalışmalar incelendiğinde, enerji tahmin çalışmalarında daha çok YSA modellerinin kullanıldığı görülmektedir. Bununla birlikte Box-Jenkins, regresyon modelleri, destek vektör regresyon ve meta-sezgisel yöntemler (Genetik Algoritma, Parçacık Sürü Optimizasyonu, Karınca Koloni Optimizasyonu) de yer almaktadır. Dünya'da enerji alanında sıklıkla kullanılan Gri tahmin çalışmalarının (Xie vd., 2015; Liu vd., 2016; Wei ve Yanfeng, 2017; He ve Lin, 2018) Türkiye'de, özellikle Türkçe literatürde sınırlı sayıda olduğu görülmektedir (Es, 2019).

$\mathrm{Bu}$ çalışma kapsamında Türkiye toplam enerji talep tahmini için 4 farklı gri tahmin modeli 
oluşturulmuştur. Zaman serisi modellerinden $\operatorname{GM}(1,1)$ ve Gri Verhulst modeli ile sebep-sonuç ilişkisine dayalı $\mathrm{GM}(0, \mathrm{~N})$ ve $\mathrm{GM}(1, \mathrm{~N})$ modelleri ile tahminler gerçekleştirilmiştir. Kurulan modellerin başarısı performans kriterlerine göre değerlendirildikten sonra geleceğe yönelik talep tahminleri yapılmıştır. Çalışmanın ilerleyen kısımları şu şekilde planlanmıştır; İkinci bölümde Gri tahmin modellerinin adımları açıklanmıştır. Üçüncü bölümde Türkiye toplam enerji talep tahmini için sistematik bir şekilde tahmin süreci işletilmiş, son bölümde ise sonuçlar ve değerlendirmeler sunulmuştur.

\section{Gri Tahmin}

Gri sistem teorisi disiplinler arası bir yaklaşım olup 1980'li yılların başında belirsizliğin sayılaştırılmasında alternatif bir metot olarak Deng tarafından ortaya atılmıştır (Deng, 1982). Gri teori, az bilgiye sahip olunan sistemler ile ilgilenir, küçük örneklem ve eksik bilginin yer aldığı problemlere çözüm bulabilmektedir (Lin ve Liu, 2004). Gri teori; sistem analizi, veri işleme, geleceği tahmin, karar verme ve sistem kontrol alanlarında yaygın olarak kullanılmaktadır (Es vd., 2018). Teoride temel amaç; stokastik veya bulanık yöntemlerle saptanamayan belirsiz sistemlerin davranışlarını, sınırlı sayıda veri yardımı ile analiz edebilmektir. (Liu ve Lin, 2006). Gri teorinin bir dalı olan gri tahmin; zaman serisi ve sebep-sonuç ilişkisine dayanan çeşitli tahmin yöntemlerini içermektedir. GM $(1,1)$, Gri Verhuslt modelleri tek tür veriye sahip modelleri ifade ederken, GM $(0, N)$ ve $\mathrm{GM}(1, \mathrm{~N})$ ise $\mathrm{N}-1$ bağımsız değişkene sahip gri modelleri ifade etmektedir.

\section{1. $G M(1,1)$}

$\operatorname{GM}(1,1)$, birçok farklı alandaki tahmin problemlerinde kullanılabilmekte ve başarılı sonuçlar elde edebilmektedir. Bir zaman serisi tahmin modeli olan $\operatorname{GM}(1,1)$ birinci dereceden tek değişkenli gri modeli ifade etmektedir. Eldeki veri sayıs1 çok az olsa dahi (en az 4 veri gerektirmekte) model kurulabilmekte ve verilerin olasılık dağılımına ilişkin bir ön bilgiye ihtiyaç duyulmamaktadır. Bu nedenle $\operatorname{GM}(1,1)$ kısıtlı veri ile çalışlabilecek rekabetçi ortamlardaki tahmin çalışmaları için uygundur. $\mathrm{GM}(1,1)$; birikimli üretim (1-AGO), gri modelleme (GM) ve ters birikimli üretim (1-IAGO) olmak üzere üç temel işleme dayanmaktadır. Model aşağıdaki adımlardan oluşmaktadır.

Adım1: Veri serisinin oluşturulması

$X^{0}$ negatif değer içermeyen, ardışık sıralı ve eşit zaman aralığındaki veri setinden oluşmaktadır.

$$
X^{0}=\left\{X_{1}^{0}, X_{2}^{0}, X_{3}^{0}, \ldots \ldots, X_{n}^{0}\right\}=\left(X_{t}^{0} ; \quad t=1,2,3, \ldots, n ; n \geq 4\right)
$$

Adım2: Birikimli serinin elde edilmesi

$\mathrm{X}^{1 \text { ‘in; }}$ yani birikimli zaman serisinin elde edilebilmesi için Denklem (3)'teki birikim üretme işlevi (AGO) uygulanmaktadır. Böylece monoton bir şekilde artan seri elde edildiği görülmektedir.

$$
\begin{aligned}
& X^{1}=\left\{X_{1}^{1}, X_{2}^{1}, X_{3}^{1}, \ldots \ldots, X_{n}^{1}\right\}=\left(X_{t}^{1} ; \quad t=1,2,3, \ldots, n ; n \geq 4\right) \\
& X_{k}^{1}=\left\{\sum_{t=1}^{k} X_{t}^{0}, t=1,2, \ldots, n ; k=1,2, \ldots, n\right\}
\end{aligned}
$$

Adım3: Gri modelin oluşturulması;

$\mathrm{X}_{\mathrm{t}}^{0}+\mathrm{a} \mathrm{Z}_{\mathrm{t}}^{1}=\mathrm{b} \quad, \mathrm{t}=2,3, \ldots, \mathrm{n}$

$\mathrm{Z}_{\mathrm{t}}^{1}=\theta \mathrm{X}_{\mathrm{t}}^{1}+(1-\theta) \mathrm{X}_{\mathrm{t}-1}^{1} ; \mathrm{t}=2,3 \ldots, \mathrm{n}$
Denklem (4)'te, a gelişim katsayısı, b ise dinamik katsayı olarak adlandırılmaktadır. $\quad[\mathrm{a} \mathrm{b}]^{T}$ katsayıları aşağıdaki gibi hesaplanır. Denklem (5)'teki $\theta$ ise yatay ayarlama katsayısı olarak ifade edilir. Ardışık komşu dizisinin ağırlığını belirlemeye yarar. Genellikle 0.5 olarak alınır. 


$$
\begin{aligned}
A & =\left[\begin{array}{l}
a \\
b
\end{array}\right]=\left(B^{T} B\right)^{-1} B^{T} Y_{N} \\
B & =\left[\begin{array}{cc}
-Z_{2}^{1} & 1 \\
-Z_{3}^{1} & 1 \\
\ldots & \ldots \\
-Z_{n}^{1} & 1
\end{array}\right] \quad Y=\left[\begin{array}{c}
\mathrm{X}_{2}^{0} \\
\mathrm{X}_{3}^{0} \\
\ldots . \\
\mathrm{X}_{\mathrm{n}}^{0}
\end{array}\right]
\end{aligned}
$$

Adım4: Beyazlaştırma işleminin gerçekleştirilmesi;

Veri beyazlaştırma işlemi aşağıdaki gibi tanımlanır:

$$
\frac{\mathrm{d} \mathrm{X}_{\mathrm{t}}^{1}}{\mathrm{dt}}+\mathrm{aX} \mathrm{X}_{\mathrm{t}}^{1}=\mathrm{b}
$$

Hesaplanan a ve b katsayılariyla diferansiyel denklem çözülerek gri tahmin eşitliği elde edillir.

$$
\hat{X}_{t+1}^{1}=\left[X_{1}^{0}-\frac{b}{a}\right] e^{-a t}+\frac{b}{a}, \quad t=0,1,2, \ldots
$$

Gri tahmin modelini oluşturabilmek ve orjinal verinin $(t+1)$ zamanındaki tahmin değerini elde etmek için, aşağıdaki ters birikim üretme işlevi (1IAGO) kullanılır.

$$
X_{t+1}^{0}=X_{t+1}^{1}-X_{t}^{1}
$$

Denklem (9), Denklem (10)'da yerine yazılırsa, Denklem (11) aşağıdaki gibi elde edilir.

$$
\hat{\mathrm{X}}_{\mathrm{t}+1}^{0}=\left(1-\mathrm{e}^{\mathrm{a}}\right)\left[\mathrm{X}_{1}^{0}-\frac{\mathrm{b}}{\mathrm{a}}\right] \mathrm{e}^{-\mathrm{at}}
$$

Oluşturulan Gri tahmin modeli ile gelecek $t$ dönemleri kullanılarak tahminler elde edilir.

\subsection{Gri Verhulst Modeli}

GM(1,1) üstellik yasasını karşılayan ve monoton değişim sürecini barındıran serilerde faydalı iken, Gri Verhulst modeli monoton olmayan dalgalı gelişim veya doymuş sigmoid serilerinde ön plana çıkmaktadır. Gri Verhulst Modelinde ikinci dereceden diferansiyel denklem kurulur. Verhulst modeli esas olarak belirli bir olgunluğa ulaşmış durumlarla süreçleri tanımlamak ve incelemek için kullanılır. İnsan popülasyonunun, biyolojik büyümenin, ürün ekonomik ömrünün vb. durumların tahmininde bu model faydalı olabilir. Gri Verhulst modelinin adımları aşağıdaki gibidir (Liu ve Lin, 2006).

Adım1: Veri serisinin oluşturulması

$X^{1}$ ardışık sıralı ve eşit zaman aralığındaki orijinal veri setini ifade eder.

$$
X^{1}=\left\{X_{1}^{1}, X_{2}^{1}, X_{3}^{1}, \ldots \ldots, X_{n}^{1}\right\}=\left(X_{t}^{1} ; \quad t=1,2,3, \ldots, n ; n \geq 4\right)
$$

Adım2: Ters birikimli serinin elde edilesi

$X^{0}$ 'in elde edilebilmesi için Denklem (14)'deki 1-IAGO uygulanmaktadır.

$$
\begin{aligned}
& X^{0}=\left\{X_{1}^{0}, X_{2}^{0}, X_{3}^{0}, \ldots \ldots, X_{n}^{0}\right\}=\left(X_{t}^{0} ; \quad t=1,2,3, \ldots, n ; n \geq 4\right) \\
& X_{k+1}^{0}=\left\{\left(X_{k+1}^{1}-X_{k}^{1}\right) ; k=1,2,3 \ldots ., n-1 ; X_{1}^{0}=X_{1}^{1}\right\}
\end{aligned}
$$

Adım3: Gri Verhulst modelin kurulması;

$$
\begin{aligned}
& X_{t}^{0}+a Z_{t}^{1}=b\left[Z_{t}^{1}\right]^{2} ; t=2,3, \ldots, n \\
& Z_{t}^{1}=\theta X_{t}^{1}+(1-\theta) X_{t-1}^{1} ; \quad t=2,3 \ldots, n
\end{aligned}
$$

$\operatorname{GM}(1,1)$ 'de olduğu gibi a gelişim katsayısını, b dinamik katsayıy ve $\theta$ ise yatay ayarlama katsayısını ifade eder. $[\mathrm{a} \mathrm{b}]^{T}$ katsayıları aşağıdaki gibi hesaplanır. 


$$
\begin{aligned}
& A=[a b]^{T}=\left(B^{T} B\right)^{-1} B^{T} Y \\
& B=\left[\begin{array}{cc}
-Z_{2}^{1} & {\left[Z_{2}^{1}\right]^{2}} \\
-Z_{3}^{1} & {\left[Z_{3}^{1}\right]^{2}} \\
\vdots & \vdots \\
-Z_{n}^{1} & {\left[Z_{n}^{1}\right]^{2}}
\end{array}\right], \quad Y=\left[\begin{array}{c}
X_{2}^{0} \\
X_{3}^{0} \\
\vdots \\
X_{n}^{0}
\end{array}\right]
\end{aligned}
$$

Adım4: Verhulst beyazlaştırma işlemiyle Gri Verhulst Modelin elde edilmesi;

$\frac{d X_{t}^{1}}{d t}+a X_{t}^{1}=b\left[X_{t}^{1}\right]^{2}$

Hesaplanan a ve b katsayllaryyla diferansiyel denklem çözülerek Gri Verhulst tahmin eşitliği elde edillir.

$\widehat{\mathrm{X}}_{\mathrm{t}+1}^{1}=\frac{\mathrm{aX}}{\mathrm{bX}_{0}^{1}+\left[\mathrm{a}-\mathrm{bX} X_{0}^{1}\right] e^{\mathrm{at}}}$

$\operatorname{GM}(1,1)$ 'de olduğu gibi ters birikim üretme işlevine gerek yoktur. Çünkü bu işlem Adım 2'de gerçekleştirilmiştir. $\mathrm{t}$ dönemleri dikkate alınarak kurulan Gri Verhulst tahmin modeli ile tahminler gerçekleştirilir.

\section{3. $G M(1, N)$}

$\operatorname{GM}(1, N)$, tek dereceden $\mathrm{N}-1$ bağımsız değişkene sahip gri modeli ifade etmektedir. Sebep-sonuç ilişkisine dayalı olarak bağımsız değişkenler ile oluşturulan tek dereceli diferansiyel çözümün zamana bağlı olarak beyazlaştırması ile sonuca ulaşır. $\operatorname{GM}(1, N)$ 'in adımları aşağıdaki gibidir.

Adım1: Veri serisinin oluşturulması

$\mathrm{X}_{1}^{0}$ bağımlı değişken serisini ifade ederken, $\mathrm{X}_{\mathrm{i}}^{0}$ bağımlı değişkeni açıklayan N-1 tane bağımsız değişken serisini ifade etmektedir.

$\mathrm{X}_{1}^{0}=\left(\mathrm{x}_{1}^{0}(1), \mathrm{x}_{1}^{0}(2), \ldots, \mathrm{x}_{1}^{0}(\mathrm{n})\right)$

$\left.X_{i}^{0}=\left(x_{i}^{0}(1), x_{i}^{0}(2), \ldots, x_{i}^{0}(n)\right) ; i=2,3, \ldots, N\right)$

Adım 2: Birikimli serinin elde edilmesi

$\mathrm{X}_{\mathrm{j}}^{1}$ tüm değişkenler için oluşturulan birikimli seriyi ifade eder. Birikim üretme işlevi ile (1AGO) ile birikimli seriler Denklem (24)'deki gibi elde edilir.

$X_{j}^{1}=\left(x_{j}^{1}(1), x_{j}^{1}(2), \ldots, x_{j}^{1}(n)\right)(j=1,2,3, \ldots, N)$

$\mathrm{x}_{\mathrm{j}}^{1}(\mathrm{t})=\sum_{\mathrm{g}=1}^{t} \mathrm{x}_{\mathrm{j}}^{0}(\mathrm{~g}) \quad(\mathrm{t}=(1,2, \ldots, \mathrm{n} ; \mathrm{n} \geq 4)$

Adım 3: N boyutlu gri diferansiyel eşitliğin oluşturulmas1

$$
\begin{aligned}
& \mathrm{x}_{1}^{0}(\mathrm{t})+a \mathrm{z}_{1}^{1}(\mathrm{t})=\sum_{i=2}^{\mathrm{N}} \mathrm{b}_{\mathrm{i}} \mathrm{x}_{\mathrm{i}}^{1}(\mathrm{t}) \\
& \mathrm{z}_{1}^{1}(\mathrm{t})=\theta \mathrm{x}_{1}^{1}(\mathrm{t})+(1-\theta) \mathrm{x}_{1}^{1}(\mathrm{t}-1) \quad \mathrm{t}=2,3, \ldots, \mathrm{n}
\end{aligned}
$$

Diğer gri modellerde olduğu gibi $\theta$, literatürde 0.5 olarak alınması önerilen yatay ayarlama katsayısını ifade eder. a gelişim katsayısı, $b_{i} x_{i}^{1}(t)$ dinamik terimleri, $b_{i}$ dinamik katsayıy ifade eder. En küçük kareler yöntemi kullanılarak A parametreleri hesaplanır.

$$
\begin{aligned}
& A=\left[\begin{array}{llll}
a b_{1} & b_{2} & \cdots & b_{N}
\end{array}\right]^{T}=\left(B^{T} B\right)^{-1} B^{T} Y \\
& B=\left[\begin{array}{cccc}
-z_{1}^{1}(2) & x_{2}^{1}(2) & \cdots & x_{N}^{1}(2) \\
-z_{1}^{1}(3) & x_{2}^{1}(3) & \cdots & x_{N}^{1}(3) \\
\vdots & \vdots & \ddots & \vdots \\
-z_{1}^{1}(n) & x_{2}^{1}(n) & \cdots & x_{N}^{1}(n)
\end{array}\right], \quad Y=\left[\begin{array}{c}
\mathrm{x}_{1}^{0}(2) \\
x_{1}^{0}(3) \\
\vdots \\
x_{1}^{0}(n)
\end{array}\right]
\end{aligned}
$$

Adım 4. Beyazlaştırma eşitliğinin oluşturulması $\operatorname{GM}(1, N)$ modelinin beyazlaştırma eşitliği aşağıda verilmiştir.

$\frac{d x_{1}^{1}}{d t}+a x_{1}^{1}=\sum_{i=2}^{N} b_{i} x_{i}^{1}$

Eşitlik çözüldüğünde aşağıdaki gibi birikimli tahmin denklemi elde edilir.

$$
\begin{aligned}
& \hat{x}_{1}^{1}(t+1)=\left[x_{1}^{0}(1)-\frac{1}{a} \sum_{i=2}^{N} b_{i} x_{i}^{1}(t+1)\right] e^{-a t}+ \\
& \frac{1}{a} \sum_{i=2}^{N} b_{i} x_{i}^{1}(t+1)
\end{aligned}
$$

Adım 5. Ters birikim üretme işlevinin uygulanmas1

Ters birikim üretme işlevi (1-IAGO) uygulanarak tahmin sonuçları elde edilir.

$\hat{\mathrm{x}}_{0}^{1}(\mathrm{t}+1)=\hat{\mathrm{x}}_{1}^{1}(\mathrm{t}+1)-\hat{\mathrm{x}}_{1}^{1}(\mathrm{t})$

Böylece A parametrelerinin hesaplanan değerleri kullanılarak $\operatorname{GM}(1, \mathrm{~N})$ modelinin gelecek tahminleri $\mathrm{t}$ dönemlerinin bağımsız değişken değerleri aracılığıyla elde edilir.

\section{4. $G M(0, N)$}

GM $(0, \quad \mathrm{~N})$ türev içermediğinden statik bir modeldir. $\mathrm{Bu}$ nedenle lineer regresyon modellerine benzer, ancak lineer regresyon modellerinden bazı temel farklılıklara sahiptir. Genel olarak, lineer regresyon modelleri orijinal veri setlerine dayanılarak oluşturulurken GM $(0$, N) modellerinin temeli orijinal veriler yerine 1AGO işlevi ile elde edilen seriler kullanır. $\mathrm{GM}(0, \mathrm{~N})$ 'nin adımları aşağıdaki gibidir. 
Adım1: Veri serisinin oluşturulması

$\mathrm{X}_{1}^{0}$ bağımlı değişken serisini ifade ederken, $\mathrm{X}_{\mathrm{i}}^{0}$ ise bağımlı değişkeni açıklayan N-1 tane bağımsız değişken serisini ifade etmektedir.

$\mathrm{X}_{1}^{0}=\left(\mathrm{x}_{1}^{0}(1), \mathrm{x}_{1}^{0}(2), \ldots, \mathrm{x}_{1}^{0}(\mathrm{n})\right)$

$\left.X_{i}^{0}=\left(x_{i}^{0}(1), x_{i}^{0}(2), \ldots, x_{i}^{0}(n)\right) ; i=2,3, \ldots, N\right)$

Adım 2: Birikimli serinin elde edilmesi

$X_{j}^{1}$ tüm değişkenler için oluşturulan birikimli seriyi ifade eder. Birikim üretme işlevi ile (1AGO) ile birikimli seriler Denklem (35)'teki gibi elde edilir.

$X_{j}^{1}=\left(x_{j}^{1}(1), x_{j}^{1}(2), \ldots, x_{j}^{1}(n)\right)(j=1,2,3, \ldots, N)$

$\mathrm{x}_{\mathrm{j}}^{1}(\mathrm{t})=\sum_{\mathrm{g}=1}^{t} \mathrm{x}_{\mathrm{j}}^{0}(\mathrm{~g}) \quad(\mathrm{t}=(1,2, \ldots, \mathrm{n} ; \mathrm{n} \geq 4)$

Adım 3: GM (0,N) modelinin oluşturulması

$\mathrm{x}_{1}^{1}=\sum_{\mathrm{i}=2}^{\mathrm{N}} \mathrm{b}_{\mathrm{i}} \mathrm{x}_{\mathrm{i}}^{1}+\mathrm{a}$

En küçük kareler yöntemi kullanılarak C parametreleri hesaplanır.

$C=\left[\begin{array}{llll}b_{1} & b_{2} & \ldots & b_{N}\end{array}\right]^{T}=\left(B^{T} B\right)^{-1} B^{T} Y$

$\mathrm{B}=\left[\begin{array}{cccc}\mathrm{x}_{2}^{1}(2) & \cdots & \mathrm{x}_{\mathrm{N}}^{1}(2) & 1 \\ \mathrm{x}_{2}^{1}(3) & \cdots & \mathrm{x}_{\mathrm{N}}^{1}(3) & 1 \\ \vdots & \ddots & \vdots & \vdots \\ \mathrm{x}_{2}^{1}(\mathrm{n}) & \cdots & \mathrm{x}_{\mathrm{N}}^{1}(\mathrm{n}) & 1\end{array}\right], \quad \mathrm{Y}=\left[\begin{array}{c}\mathrm{x}_{1}^{1}(2) \\ \mathrm{x}_{1}^{1}(3) \\ \vdots \\ \mathrm{x}_{1}^{1}(\mathrm{n})\end{array}\right]$

Adım 4. Birikimli GM $(0, N)$ tahmin modelinin elde edilmesi

Eşitlik çözüldüğünde aşağıdaki gibi birikimli tahmin denklemi elde edilir.

$\hat{\mathrm{x}}_{1}^{1}(\mathrm{t})=\left[\sum_{\mathrm{i}=2}^{\mathrm{N}} \mathrm{b}_{\mathrm{i}} \mathrm{x}_{\mathrm{i}}^{1}(\mathrm{t})+\mathrm{a}\right]$

Adım 5. Ters birikim üretme işlevinin uygulanmas1

Ters birikim üretme işlevi (1-IAGO) uygulanarak tahmin sonuçları elde edilir.

$\hat{\mathrm{x}}_{1}^{0}(\mathrm{t})=\hat{\mathrm{x}}_{1}^{1}(\mathrm{t})-\hat{\mathrm{x}}_{1}^{1}(\mathrm{t}-1)$

$\mathrm{t}$ dönemleri için bağımsız değişken değerleri dikkate alınarak gelecek dönemler tahmin edilebilir.
$\mathrm{Bu}$ bölümde 4 farklı Gri tahmin modellerinin uygulama adımları işlevsel bir şekilde gösterilmiştir. Tüm modellerle alakalı teorem ve tanımlamalar için Liu ve Lin yazmış oldukları kitapta ayrıntılı bilgiler sunmaktadır (Liu ve Lin, 2006).

\section{Bulgular ve Tartışma}

$\mathrm{Bu}$ bölüm içerisinde Türkiye'nin petrol, kömür, doğalgaz ve yenilenebilir eneji kaynakları gibi bütün enerji türlerini ifade eden toplam enerji talep tahmini çalışması gerçekleştirilmiştir. Başarılı ve güvenilir tahminleri sistematik bir şekilde elde edebilmek için; veri toplama, performans ölçütlerinin seçimi, model kurulumlarının gerçekleştirilmesi, gri model başarımlarının değerlendirilmesi ve tahmin süreçleri adım adım ele alınmıştır.

\subsection{Veri}

Çalışma kapsamında zaman serilerinin yanı sıra sebep-sonuç ilişkisine dayalı tahminler de gerçekleştirildiğinden toplam enerji tüketim verilerinin yanında literatürde kullanılan bağımsız değişkenler de irdelenmiştir. GSYH, nüfus, ithalat ve ihracat değişkenlerinin enerji talebini tahmin etmede sıklıkla kullanıldığı görülmektedir (Ceylan ve Öztürk, 2004; Kavaklığlu vd., 2009; Geem ve Roper, 2009). Bununla birlikte toplam enerji tüketimi ile ilişkili olduğu düşünülen bina yüzölçümü verilerine ulaşılarak bu parametre de bağımsız değişken olarak dikkate alınmıştır. Özellikle son çeyrek asırda Türkiye önemli ve genel olarak istikrarlı bir gelişme kaydettiğinden 1995-2018 yılları arasında ulaşılan 5 bağımsız ve bir bağımlı değişken verisi toplanmıştır. Gri tahmin modelleri az sayıda bulunan veri ile de başarılı tahminler gerçekleştirebildiğinden son çeyrek asırdaki veriler üzerinde model kurulumları gerçekleştirilmiştir. Çalışmada kullanılan tüm değişkenler ve verilerin alındığı resmi kaynaklar Tablo 1'de verilmiştir.

Tahmini gerçekleştirilecek olan toplam enerji tüketim verileri ise Şekil 1'de sunulmuştur. Toplam enerji tüketim verileri incelendiğinde bazı takip eden yıllarda hafif düşüşler ve durağanlık gözlemlense de genel olarak artan bir trende sahip olduğu söylenebilir. Verideki bu yapısal değişimin sebep-sonuç ilişkisiyle elde edilmesi ve son çeyrek asırdaki trendin ise zaman serisi ile yakalanması sağlanarak güvenilir ve güçlü tahminler oluşturulması amaçlanmıştır. 
Tablo 1. Çalışmada kullanılan değişkenler

\begin{tabular}{cc}
\hline Bağımsız Değişken & Kaynak \\
\hline GSYH & Strateji ve Bütçe Başkanlığı \\
Nüfus & Türkiye İstatistik Kurumu \\
İthalat & Türkiye İstatistik Kurumu \\
İhracat & Türkiye İstatistik Kurumu \\
Bina Yüzölçümü & Türkiye İstatistik Kurumu \\
\hline Bağımlı Değişken & \\
\hline Toplam Enerji Tüketimi
\end{tabular}

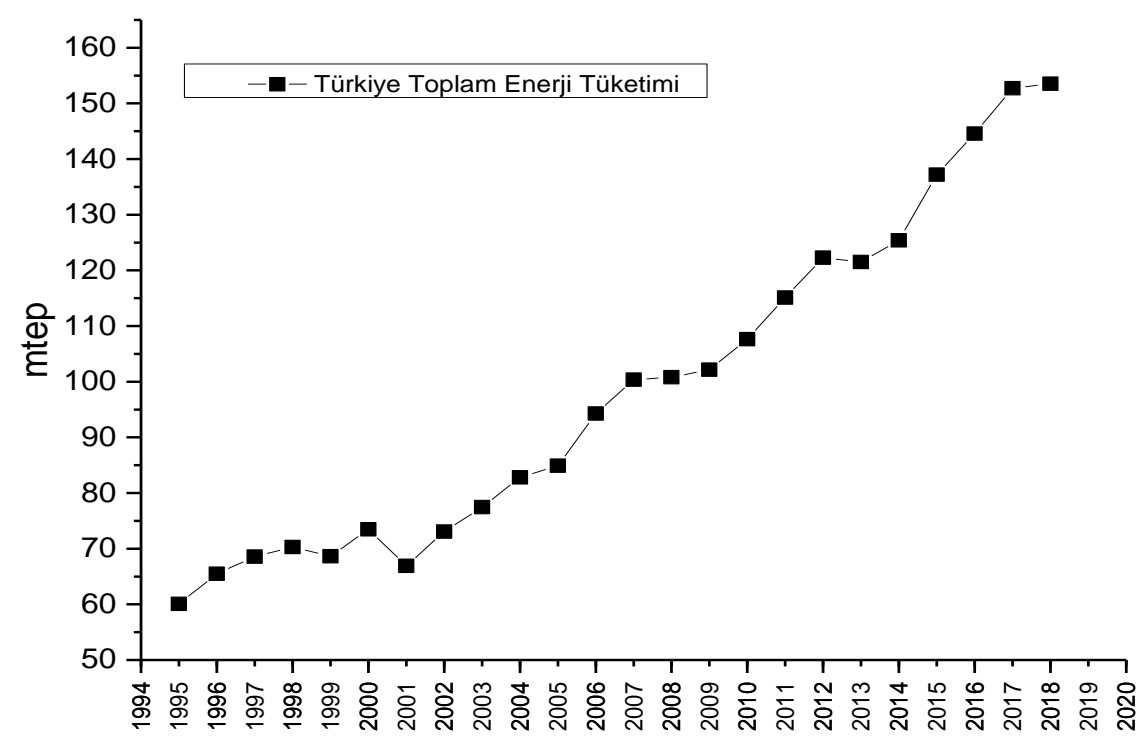

Y11

Şekil 1. 1995-2018 y1lları arası Türkiye Toplam Enerji Tüketimi

\subsection{Performans Ölçütleri}

Tahmin modellerinin doğruluğunu belirlemede birçok performans ölçütü kullanılmaktadır. $\mathrm{Bu}$ çalışmada tahmin doğruluğunu belirlemek için ortalama mutlak hata (MAE), ortalama mutlak yüzde hata (MAPE) ve hata değişim oranı (C) ölçütleri kullanılmıştır. Aşağıdaki Denklem (4143) performans ölçütlerinin hesaplanışını göstermektedir.

Ortalama Mutlak Hata $(\mathrm{OMH})=\frac{1}{n} \sum_{i=1}^{n}\left|e_{i}\right|$

Ortalama Mutlak Yüzde Hata

$(\mathrm{MAPE})=\frac{1}{n} \sum_{i=1}^{n}\left|\frac{e_{i}}{Y_{i}}\right| * 100$
Hata Değişim Oranı $(C)=\frac{\mathrm{s}_{2}}{\mathrm{~s}_{1}}$

Burada, $e_{i}$ i.hata değerini, $Y_{i}$, i. gözlem değerini, $n$ orijinal veri kümesindeki veri sayısını, $s_{1}$ orjinal veriye ilişkin standart sapmayı ve $s_{2}$ de hatalara ilişkin standart sapmayı ifade etmektedir. Her üç performans ölçütünün de düşük değerleri daha iyi tahmini göstermektedir. Literatürde MAPE'nin $\% 10^{‘}$ dan küçük olması durumunda başarılı bir tahmin gerçekleştirilmiş olduğu belirtilmektedir (Lin and Hsu, 2002). Hata değişim oranı için de iyi bir tahmine ilişkin öneriler literatürde mevcuttur (Jiang et al., 2004; Tseng vd., 2001). Her iki performans ölçütünün kabul edilebilir seviyelerine ilişkin bilgiler Tablo 2'de verilmiştir (Liu ve Lin, 2010). 
Tablo 2. Performans ölçütlerine göre doğruluk seviyeleri

\begin{tabular}{ccc}
\hline $\begin{array}{c}\text { Doğruluk } \\
\text { Seviyesi }\end{array}$ & Ölçütler & MAPE \\
\hline 1. seviye & 0.01 & 0.35 \\
2. seviye & 0.05 & 0.50 \\
3. seviye & 0.10 & 0.65 \\
4. seviye & 0.20 & 0.80 \\
\hline
\end{tabular}

\subsection{Gri Tahmin Modellerinin Kurulumu}

Gri tahmin modellerinin kurulumu için veriler eğitim ve test olmak üzere iki kümeye ayrılmıştır. 1994-2011 yılları arasındaki veriler eğitim, 20122018 verileri ise test kümesi olarak dikkate alınmıştır. GM(1,1) ve Gri Verhulst modeli için eğitim kümesinde yer alan toplam enerji tüketim verileri kullanılmıştır. Her iki model için de yatay ayarlama katsayısı 0.5 olarak alınmıştır. Eğitim kümesinin değerleri ile modeller kurulduktan sonra test kümesinin dönemi için model tahminleri yapılmıştır. Hem eğitim hem de test kümesi için modellerin üretmiş olduğu tahmin değerleri ile gerçek değerler kıyaslanarak performans ölçütleri hesaplanmıştır.

Sebep-sonuç ilişkisine dayalı tahminleri gerçekleştirmek için GM $(0,6)$ ve GM $(1,6)$ modelleri oluşturulmuştur. GSYH, nüfus, ithalat, ihracat, bina yüzölçümü bağımsız değişkenleri ile bağımlı değişken olan toplam enerji tüketim verileri ile model kurulumları yapılmıştır. Literatürde kullanıldığı gibi yatay ayarlama katsayısı 0.5 olarak alınmış ve eğitim kümesi için model adımları uygulanmıştır. Test kümesi için kurulan modellere tahminler yaptırılarak modelin başarısı test edilmiştir.

\subsection{Tahmin \\ Değerlendirilmesi}

Performanslarının

İki zaman serisi ve iki sebep-sonuç ilişkisine dayalı olarak oluşturulan toplamda dört farklı gri tahmin modelinin performans ölçütleri sırasıyla
Tablo 3'te verilmiştir. Tablo 3'deki eğitim ve test kümesi için MAPE değerleri incelendiğinde tüm modellerin $\% 10$ 'dan küçük olduğu gözlemlenmektedir. Yani kurulan her bir gri tahmin modeli kabul edilebilir düzeyde tahminler gerçekleştirebilmektedir. Performans karşılaştırmaları kendi içerisinde yapıldığında, zaman serisine dayalı bir model olan $\operatorname{GM}(1,1)$ eğitim kümesi için Gri Verhulst modeline göre daha düşük performans sergilemesine rağmen test kümesinde daha başarılı tahminlerde bulunmuştur. Ayrıca Tablo 2'de yer alan doğruluk sevilerinde göre değerlendirildiğinde GM $(1,1)$ MAPE'ye göre ikinci, hata değişim oranına göre ise birinci seviyede yer almaktadır.

Sebep sonuç ilişkisine göre performans sonuçlarına bakıldığında, GM $(0,6)$ 'nın eğitim kümesindeki performansı oldukça iyi olmasına rağmen, $\mathrm{GM}(1, \mathrm{~N})$ test kümesinde $\mathrm{GM}(0,6)$ 'ya göre daha başarılı MAPE değerine sahiptir. GM $(0,6)$ eğitim kümesindeki performans sonuçlarını test kümesinde sürdürememiştir. GM $(1,6)$ ise eğtim ve test kümesinde benzer oranda tahmin başarısına sahiptir. Test kümesi MAPE değerleri dikkate alındığında en iyi sonucu GM $(1,6)$ 'nın verdiği görülmektedir.

Test kümesi için tüm modellerin üretmiş olduğu tahmin değerleri ve gerçek değerler ile kıyaslanması Şekil 2'de verilmiştir. Şekil 2 incelendiğinde GM $(1,1)$ modelinin geçmiş zamandaki trendi yakaladığı ve buna göre test kümesini oluşturduğu görülmektedir.

Tablo 3. Gri tahmin modellerinin performans ölçüt değerleri

\begin{tabular}{ccccccc}
\hline & \multicolumn{3}{c}{ Eğitim Kümesi } & \multicolumn{3}{c}{ Test kümesi } \\
\hline & MAE & MAPE (\%) & C & MAE & MAPE (\%) & C \\
\hline GM(1,1) & 3.12 & 4.03 & 0.23 & 4.73 & 3.35 & 0.29 \\
Gri Verhulst & 2.80 & 3.59 & 0.21 & 9.15 & 6.48 & 0.48 \\
GM(0,6) & 1.31 & 1.57 & 0.06 & 4.62 & 3.55 & 0.34 \\
GM(1,6) & 2.41 & 3.20 & 0.20 & 4.26 & 3.31 & 0.36 \\
\hline
\end{tabular}


Gri Verhulst modeli ise olgun sinüs hareketine benzer şekilde hızlı bir trend artışı göstermektedir. $\mathrm{Bu}$ durum test kümesi için performans ölçütlerine bakıldığında belirgin olarak görülmektedir. Sebep-sonuç ilişkisine dayalı tahmin yapan $\operatorname{GM}(0,6)$ ve GM $(1,6)$ 'nın test kümesinde birbirine oldukça yakın sonuç verdiği gözlemlenmiştir. Gerçekleşen toplam enerji tüketimindeki artış ve azalışları zaman serisine ilişkin modellerden daha iyi yakalayabildiği söylenebilir.

GM $(1,1)$ ve GM $(1,6)$ modellerinin test kümesindeki tahmin performansları birbirine yakındır. Farklı performans ölçütlerine göre birbirlerine üstünlük sağlamaktadırlar. GM $(1,1)$ geçmiş dönemdeki trendi yakalayabildiğinden gelecekte de benzer trendin olacağ 1 durumu tahmin edebilecektir. GM $(1,6)$ modeli ise bağımsız değişken kullanması nedeniyle gelecek dönemler için senaryo türetilmesine imkân vermektedir. Bu nedenle düşük ve yüksek senaryo durumları dikkate alınarak GM $(1,6)$ modeli ile tahminler gerçekleştirilecektir. Böylece hem zaman serisi hem de sebep sonuç ilişkisine dayalı gri tahmin modelleri ile toplam enerji talebi tahmin edilmiş olacaktır.

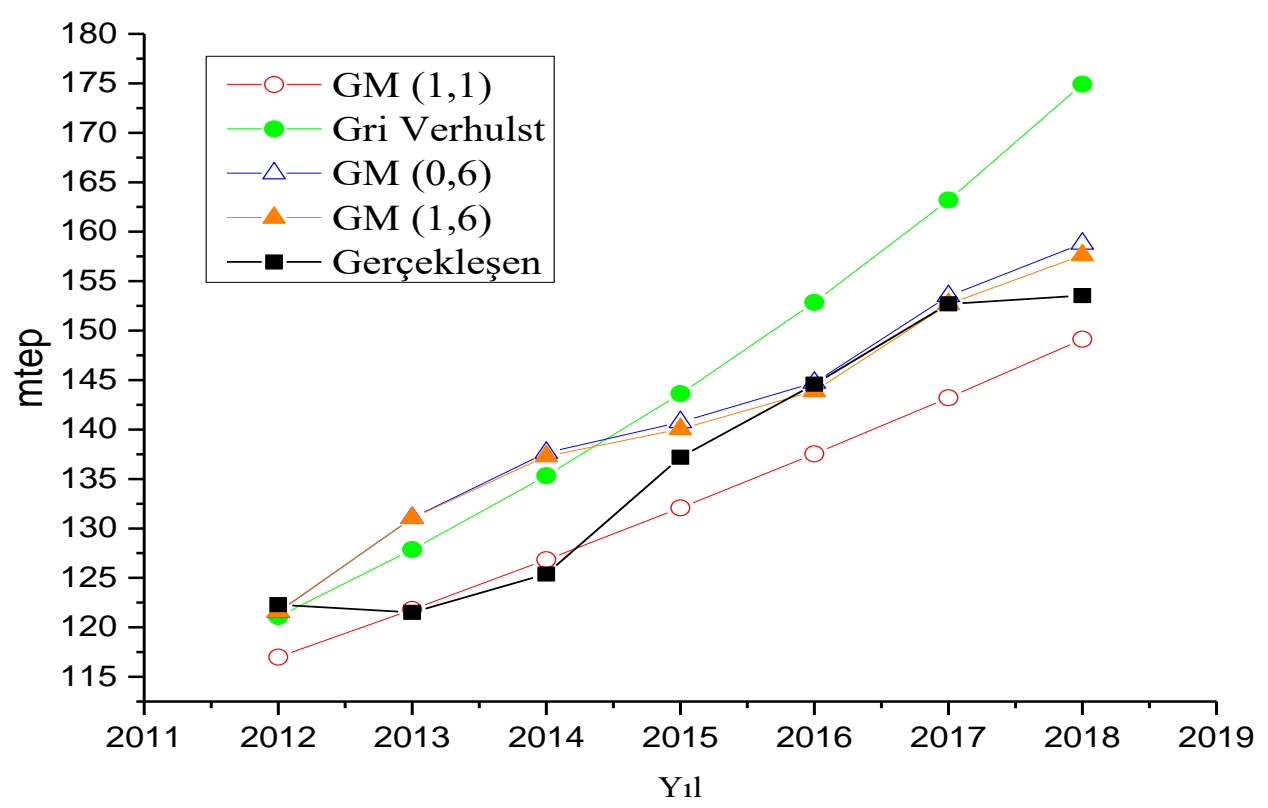

Şekil 2. Test kümesi için gri tahmin modellerinin performanslarının karşılaştırılması

\subsection{Tahmin}

GM $(1,6)$ ile gelecek toplam enerji talebini tahmin edebilmek için kullanılan bağımsız değişkenlerin gelecek değerlerinin bilinmesi gerekmektedir. Mevcut durumdan farklı koşulları öngörebilmek adına düşük ve yüksek olmak üzere iki farklı senaryo oluşturulmuştur. Nüfus bağımsız değişkeni için TÜİK yıl ortası nüfus verileri kullanılmıştır. Diğer bağımsız değişkenler için geçmiş dönemdeki artış ve azalış oranları dikkate alınarak yüzdelik değerler belirlenmiştir. Düşük senaryoda; ekonomik gelişmenin yavaşladığ 1 pozitif yönde hafif iyileşmenin devam ettiği durum ele alınmıştır. Yüksek senaryoda ise, genel olarak ortalama ve ortalamanın üzerinde değerlerle sürecin pozitif şekilde devam ettiği durum ortaya koyulmuştur. Senaryolara göre bağımsız değişkenlerin yüzdelik değerleri Tablo 4'de sunulmuştur.

Tablo 4. Senaryolara göre yüzdelik değerler

\begin{tabular}{ccccc}
\hline & GSYH & İthalat & İhracat & Bina Yüzölçümü \\
\hline Düşük Senaryo & $1.30 \%$ & $1.90 \%$ & $2.20 \%$ & $1.20 \%$ \\
Yüksek Senaryo & $5.20 \%$ & $12.20 \%$ & $14.20 \%$ & $9.60 \%$ \\
\hline
\end{tabular}

GM $(1,6)$ ile senaryolara göre oluşturulan bağımsız değişken değerleri kullanılarak 2025 y1lına kadarki Türkiye toplam enerji talebi tahmin edilmiştir. GM $(1,1)$ modeli ile de tahmin edilmek istenen dönem sayısı dikkate alınarak 2025 yılına kadarki tahminler gerçekleştirilmiştir. Elde edilen tüm tahmin değerleri Tablo 5'te sunulmuştur. Elde edilen tahmin sonuçlarının grafiği ise Şekil 3'te oluşturulmuştur. 
Tablo 5. Senaryo ve Gri tahmin modellerine göre Türkiye toplam enerji talebi

\begin{tabular}{cccc}
\hline Yıllar & Düşük Senaryo GM (1,6) (mtep) & GM (1,1) (mtep) & Yüksek Senaryo GM (1,6) (mtep) \\
\hline $\mathbf{2 0 1 9}$ & 159.92 & 155.28 & 166.19 \\
$\mathbf{2 0 2 0}$ & 162.31 & 161.69 & 175.43 \\
$\mathbf{2 0 2 1}$ & 164.72 & 168.36 & 185.34 \\
$\mathbf{2 0 2 2}$ & 167.16 & 175.32 & 195.99 \\
$\mathbf{2 0 2 3}$ & 169.64 & 182.55 & 207.43 \\
$\mathbf{2 0 2 4}$ & 172.13 & 190.09 & 219.74 \\
$\mathbf{2 0 2 5}$ & 174.66 & 197.94 & 232.99 \\
\hline
\end{tabular}

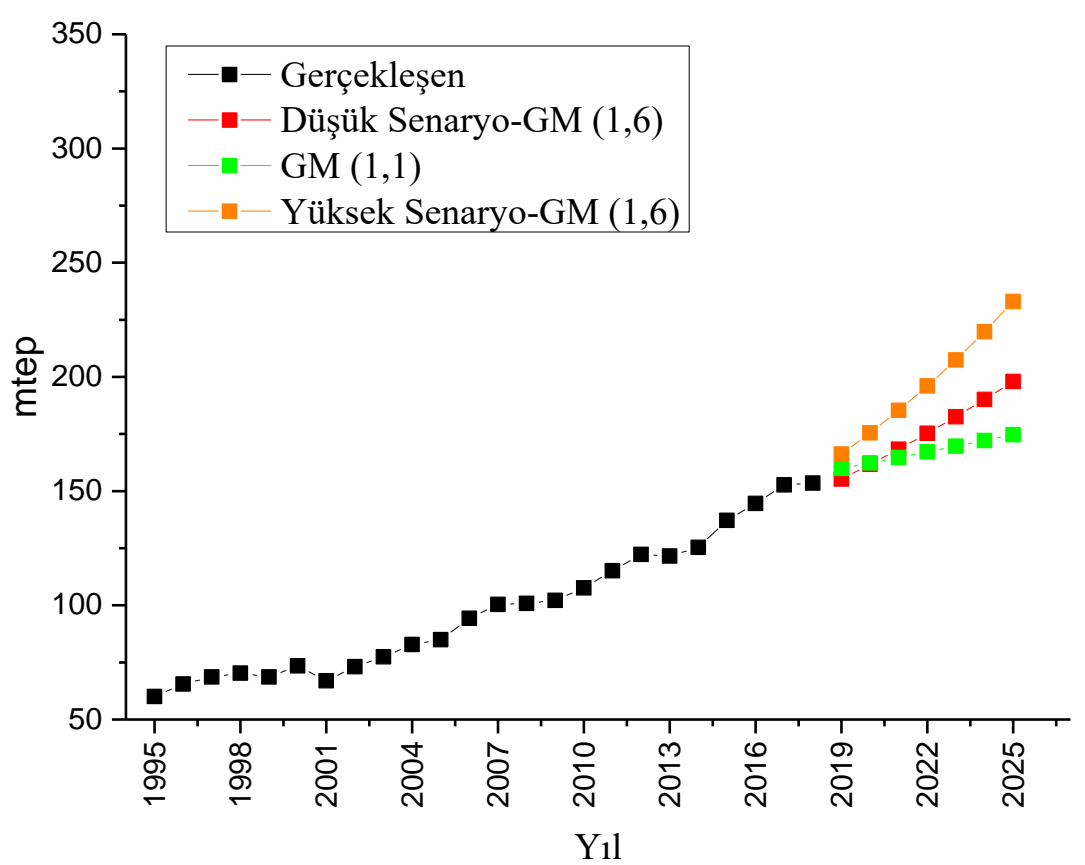

Şekil 3. Gri tahmin modeller ile Türkiye toplam enerji talep tahmini

Çalışma kapsamında hem zaman serisi hem de sebep sonuç ilişkisine dayalı gri tahmin modelleri oluşturulmuştur. Gri modeller az veri ile çalışabilme özelliği ile ön plana çıkmaktadır. Ayrica bu modeller kolay kodlanabilmekte ve her koşum neticesinde deterministik değerler elde edebilmektedir. Detaylı parametre analizine ve birden fazla koşuma ihtiyaç duymamaktadır. Literatürde bu yöntemlerin bir arada kullanıldığ kapsamlı bir çalışma yer almamaktadır. Bu çalışmada; hem zaman serisine yönelik olarak, hem de yüksek ve düşük senaryo bazlı sebepsonuç ilişkisine dayalı gri tahmin modellerinin bir arada kullanımı sunulmuş ve böylece gri modellerin enerji talep tahminindeki başarısı gösterilmiştir. Üstünlüğü saptanan modeller ile geleceğe yönelik, doğruluğu yüksek ve güvenilir tahminler elde edilmiştir.

\section{Sonuçlar}

Stratejik öneme sahip enerjinin gelişen ve gelişmekte olan ülkeler için gelecek dönem projeksiyonlarının yapılmasına ihtiyaç duyulmaktadır. Başarılı ve güvenilir projeksiyonlar sayesinde gelecek enerji politikalarının belirlenmesi, gerekli tedbirlerin alınması, enerji yatırımlarının planlanması mümkün olabilecektir. Az sayıda veri kullanım özelliği ile ön plana çıkan Gri tahmin modelleri birçok farklı alanda başarılı tahminler elde edebilmektedir. Bu çalışmada, son çeyrek asırda önemli ekonomik ve sosyal gelişim gösteren Türkiye'nin toplam enerji talebi tahmin edilmiştir. Gri tahmin, zaman serisi ve sebep-sonuç ilişkisine dayalı tahminler gerçekleştirebilmektedir. Çalışma kapsamında; zaman serisi modellerinden $\operatorname{GM}(1,1)$ ve Gri Verhulst ile sebep-sonuç ilişkisine dayalı $\operatorname{GM}(0,6)$ ve $\operatorname{GM}(1,6)$ modelleri olmak üzere 4 farklı gri tahmin modeli kurulmuştur. Kurulan gri modellerin performansı değerlendirildiğinde MAPE değerlerinin kabul edilebilir seviye olan $\% 10$ değerinin altında yer aldığı gözlemlenmiştir. Dikkate alınan tüm performans ölçütleri değerlendirildiğinde $\operatorname{GM}(1,1)$ ve $\operatorname{GM}(1,6)$ modellerinin daha başarılı sonuçlar ürettiği gözlemlenmiştir. Zaman serisi modeli olan GM $(1,1)$ ile gelecek tahminler yapılmış, böylelikle 
geçmiş dönemdeki trendin gelecek dönemde de devam ettiği tahminler elde edilmiştir. Sebepsonuç ilişkisine dayalı bir model olan GM $(1,6)$ ' da ise GSYH, nüfus, ithalat, ihracat ve bina yüzölçümü bağımsız değişkenleri kullanılmıştır. Muhtemel düşük ve yüksek senaryolar oluşturularak tahminler elde edilmiştir. Sonuç olarak başarılı ve güvenilir tahmin yapabildiği saptanan GM $(1,1)$ ve GM $(1,6)$ modelleri ile Türkiye'nin toplam enerji talebinin 2025 yilına kadarki düşük, beklenilen ve yüksek tahmin değerleri bir arada sunulmuştur. 2025 y1lında yüksek senaryoya göre toplam enerji talebinin 232 mtep, mevcut trendin devam etmesi durumda 198 mtep ve düşük senaryo da ise 175 mtep civarında olması beklenmektedir.

Gri tahmin modelleri ile enerji talebine yönelik olarak literatürde çeşitli çalışmalar bulunmasına karşın, Türkiye'de sınırlı çalışmaların yer aldığı görülmektedir. Bu çalışma da bu noktada Türkçe literatüre katkıda bulunmaktadır. Çalışmadan elde edilen sonuçlar enerji ile ilgili devlet kurumlarına, özel sektöre ve tüm karar vericilere hitap etmektedir. Elde edilen başarılı ve güvenilir tahmin değerleri enerji de dışa bağımlı olan Türkiye'nin sürdürülebilir enerji politikalarının belirlenmesinde yardımcı olacaktır. Gelecek çalışmalarda, Gri tahmin modellerinin yanı sıra diğer tahmin yöntemleri kullanılarak kıyaslamalar ve tahminler gerçekleştirilebilir. Ayrıca çalışma sonucunda elde talep tahmin değerleri, emisyon miktarının modellenmesinde girdi olarak kullanılarak çevresel etki değerlendirme çalışmalarına katkı sağlayabilir.

\section{Kaynaklar}

Aydin, G., 2014. Modeling of Energy Consumption Based on Economic And Demographic Factors: the Case of Turkey with Projections. Renewable and Sustainable Energy Reviews, 35, 382-389.

Bayramoğlu, T., Pabuçcu, H., ve Boz, F. Ç., 2017. Türkiye için Anfis Modeli ile Birincil Enerji Talep Tahmini. Ege Akademik Bakış, 17(3), 431-445.

Bessec, M., ve Fouquau, J., 2008. The Non-Linear Link between Electricity Consumption and Temperature in Europe: a Threshold Panel Approach. Energy Economics, 30(5), 27052721.

Boran, K., 2014. The Box Jenkins Approach to Forecast Net Electricity Consumption in Turkey. Energy Sources, Part A: Recovery, Utilization, and Environmental Effects, 36(5), 515-524.
BP, 2019. Statistical Review of World Energy Workbook,:

Https://www.bp.com/en/global/corporate/energy -economics/statistical-review-of-worldenergy.html

Ceylan, H., ve Ozturk, H. K., 2004. Estimating Energy Demand of Turkey Based on Economic Indicators using Genetic Algorithm Approach. Energy Conversion and Management, 45(1516), 2525-2537.

Es, H. A., 2019. Comparison of Direct and Iterative Grey Prediction Models for Natural Gas Demand, 3rd International Web Conference on Forecasting, November 2019, Giresun, Turkey, s.28-34.

Es, H. A., Hamzacebi, C., ve Firat, S. U. O., 2018. GRA-TRI: A Multicriteria Decision Aid Classification Method based on Grey Relational Analysis. The Journal of Grey System, 30(3), 113.

Es, H. A., Kalender, F. Y., ve Hamzaçebi, C., 2014. Yapay Sinir Ağlari ile Türkiye Net Enerji Talep Tahmini. Gazi Üniversitesi MühendislikMimarlık Fakültesi Dergisi, 29(3), 495-504.

Geem, Z. W., ve Roper, W. E., 2009. Energy Demand Estimation of South Korea Using Artificial Neural Network. Energy Policy, 37(10), 40494054.

Hamzacebi, C., ve Es, H. A., 2014. Forecasting the Annual Electricity Consumption of Turkey Using an Optimized Grey Model. Energy, 70, 165-171.

Hamzaçebi, C., Es, H.A. ve Çakmak, R., 2019. Forecasting of Turkey's Monthly Electricity Demand by Seasonal Artificial Neural Network. Neural Computing and Applications 31, 22172231.

He, Y., ve Lin, B., 2018. Forecasting China's Total Energy Demand and its Structure Using ADLMIDAS Model. Energy, 151, 420-429.

Jiang, Y., Yao, Y., Deng, S., ve Ma, Z., 2004. Applying Grey Forecasting to Predicting the Operating Energy Performance ff Air Cooled Water Chillers. International Journal of Refrigeration, 27(4), 385-392.

Kavaklioglu, K., Ceylan, H., Ozturk, H. K., ve Canyurt, O. E., 2009. Modeling and Prediction of Turkey's Electricity Consumption Using Artificial Neural Networks. Energy Conversion and Management, 50(11), 2719-2727.

Kucukali, S., ve Baris, K., 2010. Turkey’s Short-Term Gross Annual Electricity Demand Forecast by 
Fuzzy Logic Approach. Energy Policy, 38(5), 2438-2445.

Lee, Y. S., ve Tong, L. I., 2011. Forecasting Energy Consumption Using a Grey Model Improved by Incorporating Genetic Programming. Energy Conversion and Management, 52(1), 147-152.

Lin, C. T., ve Hsu, P. F., 2002. Forecast of NonAlcoholic Beverage Sales in Taiwan Using the Grey Theory. Asia Pacific Journal of Marketing and Logistics, 14(4), 3-12.

Lin, Y., Liu S., 2004. A Historical Introduction to Grey Systems Theory. 2004 IEEE International Conference on Systems, Man and Cybernetics, 3, 2403-2408.

Liu, S., ve Forrest, J. Y. L., 2010. Grey Systems: Theory and Applications. Springer Science \& Business Media, 379p.

Liu, S., ve Lin, Y., 2006. Grey Information: Theory and Practical Applications. Springer Science \& Business Media, 508p.

Liu, X., Moreno, B., ve García, A. S., 2016. A Grey Neural Network and Input-Output Combined Forecasting Model. Primary Energy Consumption Forecasts in Spanish Economic Sectors. Energy, 115, 1042-1054.

Salcedo-Sanz, S., Muñoz-Bulnes, J., Portilla-Figueras, J. A., ve Del Ser, J., 2015. One-Year-Ahead Energy Demand Estimation from Macroeconomic Variables Using Computational Intelligence Algorithms. Energy Conversion and Management, 99, 62-71.

Salisu, A. A., ve Ayinde, T. O., 2016. Modeling Energy Demand: Some Emerging Issues. Renewable and Sustainable Energy Reviews, 54, 1470-1480.

Sánchez-Oro, J., Duarte, A., ve Salcedo-Sanz, S., 2016. Robust Total Energy Demand Estimation with a Hybrid Variable Neighborhood Search-Extreme Learning Machine Algorithm. Energy Conversion and Management, 123, 445-452.
Suganthi, L., ve Samuel, A. A., 2012. Energy Models for Demand Forecasting - a Review. Renewable and sustainable energy reviews, 16(2), 12231240 .

Tseng, F. M., Yu, H. C., ve Tzeng, G. H., 2001. Applied Hybrid Grey Model to Forecast Seasonal Time Series. Technological Forecasting and Social Change, 67(2-3), 291302.

TUIK, 2020, Türkiye İstatistik Kurumu: Temel İstatistik Göstergeler, Http://www.tuik.gov.tr/UstMenu.do?metod=tem elist

Ünler, A., 2008. Improvement of Energy Demand Forecasts Using Swarm Intelligence: The Case of Turkey with Projections to 2025. Energy Policy, 36(6), 1937-1944.

Wang, Q., Li, S., ve Li, R., 2018. Forecasting Energy Demand in China And India: Using SingleLinear, Hybrid-Linear, and Non-Linear Time Series Forecast Techniques. Energy, 161, 821831.

Wei, S., ve Yanfeng, X., 2017. Research on China's Energy Supply and Demand Using an Improved Grey-Markov Chain Model Based nn Wavelet Transform. Energy, 118, 969-984.

Wen, K.L., 2004. Grey Systems: Modeling and Prediction, Yang's Scientific Research Institute, YangSky Scientific Press, 253p.

Worldbank, 2020. Dünya Bankası İstatistikleri, Https://data.worldbank.org/indicator/SP.POP.T OTL?locations $=$ TR

Xie, N. M., Yuan, C. Q., ve Yang, Y. J., 2015. Forecasting China's Energy Demand and SelfSufficiency Rate by Grey Forecasting Model and Markov Model. International Journal of Electrical Power and Energy Systems, 66, 1-8. 